
\title{
$\begin{array}{ll}\text { Research Square } & \begin{array}{l}\text { Preprints are preliminary reports that have not undergone peer review. } \\ \text { They should not be considered conclusive, used to inform clinical practice, } \\ \text { or referenced by the media as validated information. }\end{array}\end{array}$
}

\section{The association between mental health and physical fitness in Norwegian adolescents}

\author{
Andreas Åvitsland ( $\nabla$ andreas.avitsland@uis.no ) \\ Universitetet i Stavanger https://orcid.org/0000-0003-4357-1615 \\ Eva Leibinger \\ Universitetet i Stavanger
}

\section{Tommy Haugen}

Universitetet i Agder

\section{Øystein Lerum}

Hogskulen pa Vestlandet

\section{Runar Barstad Solberg}

Norges idrettshogskole

Elin Kolle

Norges idrettshogskole

\section{Sindre Mikal Dyrstad}

Universitetet i Stavanger

\section{Research article}

Keywords: physical fitness, mental health, strengths and difficulties, Norway, adolescence, cross-sectional

Posted Date: January 24th, 2020

DOI: https://doi.org/10.21203/rs.2.21851/v1

License: (c) (i) This work is licensed under a Creative Commons Attribution 4.0 International License.

Read Full License

Version of Record: A version of this preprint was published at BMC Public Health on May 24th, 2020. See the published version at https://doi.org/10.1186/s12889-020-08936-7. 


\section{Abstract}

Background: Studies indicate that cardiorespiratory fitness, muscular strength and body composition are associated with mental health. However, research is scarce concerning this relationship in young adolescents in general and non-existent in Norwegian populations specifically. The aim of the study was to examine the relationship between different health-related aspects of physical fitness and self-reported mental health in Norwegian adolescents.

Methods: Participants from four regions of Norway $(n=1486$; mean age $=13.9$; girls $=50.6 \%)$ completed the Strengths and Difficulties Questionnaire, and were measured for cardiorespiratory fitness, muscular strength and body composition. Linear mixed effects models were conducted to assess the associations between the health-related aspects of physical fitness and the total difficulties score of the questionnaire.

Results: Body composition was not associated with total difficulties score. Muscular strength independently was associated with total difficulties score, but when all independent variables were entered in the fully adjusted model, only cardiorespiratory fitness was associated with total difficulties score. School clusters were included as random effects and all models were controlled for sex, socioeconomic status and birthplace (domestic or foreign).

Conclusions: A small but significant negative association between cardiorespiratory fitness and total difficulties score indicated that higher cardiorespiratory fitness predicted better mental health in Norwegian adolescents. The results suggest that muscular strength is not associated with mental health in adolescents, when controlling for cardiorespiratory fitness. Future research on how exercise affects mental health should investigate whether there is a greater effect for participants who improve their cardiorespiratory fitness.

\section{Background}

"Mental health is defined as a state of well-being in which every individual realizes his or her own potential, can cope with the normal stresses of life, can work productively and fruitfully, and is able to make a contribution to her or his community" [1]. Mental health problems affect between 10 and $20 \%$ of the global child and adolescent population [2] and approximately $18 \%$ of adults will have experienced a form of mental disorder within a one-year period [3]. Depression is the most prevalent mental disorder, accounting for $41 \%$ of all disability-adjusted life years caused by mental and substance use disorders [4]. Adolescent mental health problems have increased during recent decades in middle- and high-income countries [5]. Although part of the increase may be attributed to more awareness, help-seeking, and a lower threshold for treatment, a real prevalence increase for mental health problems has likely occurred. In Norway, the percentage of lower secondary school girls reporting depressive symptoms has increased from 16\% in 2011 to $20 \%$ in 2016 [6]. Furthermore, at the end of upper secondary school, $12 \%$ of boys and $29 \%$ of girls display high levels of depressive symptoms. 


\section{Physical activity, physical fitness and potential mechanisms}

Evidence suggests physical activity is a protective factor against mental health problems such as depression [7]. Moreover, physical activity can positively affect a range of other mental health outcomes, such as mood, stress, cognitive functioning [8], and self-worth [9]. Although there is no clear consensus, many mechanisms have been hypothesized to explain the relationship between physical activity and mental health. Lubans et al. [10] elucidated three of these mechanisms. First, the neurobiological mechanism proposes that physical activity alters structural and functional compositions of the brain. Second, the psychosocial mechanism proposes that physical activity can provide social interaction, physical mastery, independence and improved appearance self-perception. Lastly, the behavioral mechanism proposes that changes in behavior, such as sleep and coping skills, mediates how physical activity affects mental health outcomes.

While our physical activity level fluctuates from week to week, physical fitness, although somewhat influenced by genes [11], represents the type, frequency, intensity and duration of physical activity that has occurred over time [12]. Physical fitness may therefore provide a more stable measure of habitual physical activity levels. Physical fitness can be divided into health-related aspects, such as cardiorespiratory fitness (CRF), muscular strength, and body composition [13]. Given the relationship between physical activity and physical fitness, the mechanisms proposed to explain the relationship between physical activity and mental health might also apply for physical fitness and mental health [14]. However, the aforementioned aspects of physical fitness may also be associated with mechanisms influencing mental health outcomes, independent from physical activity [15]. High CRF, as a result of vigorous aerobic physical activity [16] can affect neurobiological processes and inhibit inflammation [14]. Body composition affects body image [17], which in turn depends on cultural norms [18]. Therefore, body composition may affect mental health outcomes through sociocultural or psychosocial mechanisms, in addition to the possible biological mechanisms that are associated with obesity [19]. Muscular strength may also depend on cultural norms [20], thereby possibly affecting mental health through similar mechanisms as body composition. Additionally, muscular strength may affect neurobiological processes differently than CRF, however, this is unclear [21].

\section{Mental health and physical fitness in adolescents}

Few studies have examined the relationship between mental health outcomes and physical fitness in adolescent populations. Ruggero et al. [22], showed that CRF was inversely associated with depression in 12- and 13-year-old girls $(r=-.31)$ and boys $(r=-.39)$. Another study found that adolescent girls with low CRF exhibited $31 \%$ higher levels of depression, compared to girls with high CRF [23]. The same study also showed that boys and girls categorized as having a fit body composition exhibited $12 \%$ and $25 \%$ higher body satisfaction, respectively, compared to students categorized as having an unfit body composition. Regarding muscular strength, Lubans and Cliff [24] found an association with self-worth in boys but not girls, and a review by Smith et al. [25] showed a strong association with self-esteem in adolescent populations. 


\section{Aim}

Considering how mental health problems that occur in adolescence can persist into adulthood [26], effective methods to prevent these problems, or to improve adolescent mental health is important. A small amount of evidence regarding adolescents indicates a relationship between the aspects of healthrelated physical fitness and mental health outcomes. However, to the best of our knowledge, only the study by Yeatts, Martin and Petrie [27] has measured the three aspects CRF, muscular strength and body composition in association with a mental health outcome in adolescents. Thus, it is unclear whether one aspect is more important than others. Regarding Norwegian adolescents specifically, only one study has examined a mental health outcome in association with physical fitness [28]. Therefore, the aim of the present paper was to investigate the relationship between health-related aspects of physical fitness and mental health in Norwegian adolescents.

\section{Methods}

\section{Design and participants}

The present study used cross-sectional data from the baseline tests of the School in Motion project [29]. This was a multicenter study, involving four geographically separate regional test centers in Norway. Out of 103 invited lower secondary schools, 29 schools agreed to participate. Only eighth grade students were invited to participate in the study $(n=2733)$. Informed parental consent was obtained from $76 \%$ of the invited students $(n=2084)$. Not all students had valid measures on all variables and Fig. 1 shows an overview of the participant flow. The participants were tested in the spring of 2017, during school time, at their respective schools. All test personnel received the same training beforehand to make sure there were no discrepancies in how the tests were carried out. All test procedures were approved by the Norwegian Centre for Research Data (project number 49094), and the project is in accordance with the Declaration of Helsinki for experiments involving humans.

\section{Measurements}

\section{Body composition}

Participants' weight without shoes was measured by digital scale (Seca 899, Hamburg, Germany) and all measurements were recorded to the closest $0.1 \mathrm{~kg}$. Their clothes were noted, and their weight adjusted in the following analysis: $1 \mathrm{~kg}$ was subtracted for pants and/or sweater, $0.5 \mathrm{~kg}$ was subtracted for shorts/tights and t-shirt. Height was measured by portable stadiometer (Seca 123, Hamburg, Germany) and was recorded to the closest $\mathrm{mm}$. The values were used to calculate individual BMI scores $\left(\mathrm{kg} / \mathrm{m}^{2}\right)$. None of the measurements were disclosed to the participants.

\section{Muscular strength}


Sit-ups (n/30 seconds), standing broad jump (best of two attempts) and handgrip test (best of two attempts), as described in the EUROFIT test battery [30] were used to measure muscular strength. Participants performed sit-ups with their knees in a 90-degree angle and their fingers locked behind their head, and their feet held to the floor by test personnel. To get a valid count, the participants had to touch their knees with their elbows, going up, and touch the floor with their shoulders, going down. Participants performed standing broad jump by jumping as far as they could from a stand still position, and the distance was recorded from the heel closest to the starting point. Measurements were recorded to the closest $\mathrm{cm}$. The handgrip strength test was executed with the participants' dominant hand, as they held their arm down alongside their body, gripping a Baseline dynamometer (Baseline® Hydraulic Hand Dynamometer, Elmsford, NY, USA) as hard as they could for three seconds. Measurements were recorded to the closest kg.

\section{Cardiorespiratory fitness}

CRF was assessed by a 10-minute intermittent running test [31] The test was performed by the participants running between two marked lines, 16 meters apart, inside a gymnasium. The participants ran for 15 seconds, then paused for 15 seconds on the test leader's whistle. They were required to touch the floor behind the line with one hand before turning and running back. The procedure was repeated for 10 minutes. According to test protocol, the intended distance between the lines is 20 meters; however, limited space in many school gymnasiums compelled us to set a new standard distance at 16 meters.

\section{Mental health}

To measure mental health, the participants completed a Norwegian language version of the Strengths and Difficulties Questionnaire [SDQ; 32]. The questionnaire consists of 25 items divided into five subscales. The five subscales cover emotional symptoms, conduct problems, hyperactivity, peer relationships and prosocial behavior. The questionnaire contains statements such as "I worry a lot", "I am easily distracted, I find it difficult to concentrate" and "Other people my age generally like me". Participants reply to the statements on a three-point Likert scale: "not true", "somewhat true" and "certainly true". Each subscale scores from 0 to 10. Except for the prosocial subscale, a higher score signifies a higher degree of difficulties. A high score on the prosocial subscale signifies social strengths. The scores from all subscales except the prosocial are summed to create the total difficulties score (TDS). TDS scores from $0-40$ and is a dimensional measure of mental health for children and adolescents, which means that on a population level, there is a detectable reduction in psychopathology for each point-reduction on the scale [33]. It therefore represents an indication of the general mental health state in the measured population. The psychometric properties of the SDQ have been validated in several countries [34-36], including Norway [37].

\section{Covariates}

Other variables associated with mental health are sex [38], domestic or foreign birthplace [39], and socioeconomic status [SES; 40]. The participants' sex was noted by test-personnel, and birthplace ("Were 
you born in Norway") was assessed in the questionnaire. Parents' education level was included as a measure of SES [41].

\section{Statistical analysis}

\section{Data management}

Data were managed and analyzed in IBM SPSS Statistics 25 (IBM, Armonk, New York, USA). SDQ data were scored according to the syntax provided by the SDQ information web page [42]. The syntax summed the scores from each of the four subscales needed to create the TDS variable. Cronbach's alpha was employed to assess the internal consistency of TDS and the result was .62.

A mean total z score for muscular strength was composed from handgrip strength, standing broad jump and sit-ups. SES was analyzed by including only the parent with the highest education level. Next, the education level was categorized as either "lower secondary school or less", "upper secondary school", "less than four years university education" and "four years or more university education".

Out of 2045 participants, $27 \%(n=559$; girls $=38.2 \%)$ had at least one missing value. A new grouping variable was created to analyze differences between participants with all values $(n=1486)$ and participants with missing values $(n=559)$. The following primary analyses were carried out on the complete-case group only, while extensive missing value analyses were conducted to examine if they influenced the primary results.

\section{Complete-case primary analyses}

Descriptive statistics were calculated and are presented as means and standard deviations (SD). Four linear mixed effect models with TDS as the dependent variable were conducted, in order to assess associations for each health-related aspect of physical fitness, separately and controlling for each other. All covariates (sex, domestic birthplace and SES) were entered as independent variables in all models. We report estimates (regression coefficients) and their $95 \%$ confidence intervals. Estimates reflect the change in TDS as a result of one unit of measurement change in the independent variables. Initial linear mixed effect modelling showed no statistically significant interaction effects between sex and the physical fitness variables, using TDS as the dependent variable. To account for possible effects of clustering of observations within schools, school site was included as a random effect in all models. A p value $<.05$ indicated statistical significance.

\section{Missing value analyses}

To assess whether missing values were missing completely at random (MCAR), Little's MCAR test was used. The analysis did not support MCAR $(104.331, \mathrm{DF}=24, \mathrm{p}<.001)$. Pattern analysis (not shown) indicated that the data were likely missing at random (MAR). A possible explanation for the missing values is that we never forced the participants to complete the tests, which may have caused some participants to opt out. For instance, many stated that they did not want to run the CRF test. Moreover, the SDQ was one of many components in a large and extensive questionnaire. The missing data from the 
SDQ may be a consequence of the size and duration of the extended questionnaire, which may have caused many to quit before completion. However, this is unclear and there may be other reasons unknown to us.

One-way ANOVA was used to assess differences between the complete-case group and the missingvalues group. Pearson's correlation analysis was used on the fitness variables and TDS, for the purpose of examining if associations were similar in both groups. Multicenter studies are vulnerable to differences in missingness between test centers [43], and this was examined using frequency statistics. As our final action in handling the missing values, we employed multiple imputation [44, 45]. Five imputations were generated from relevant variables, using the automatic procedure with 10 iterations, with the assumption that data were missing at random. A linear mixed effects model was conducted on the imputed dataset, with TDS as the dependent variable, and all health-related aspects of physical fitness variables and covariates entered as independent variables. The imputed dataset results are presented, in addition to the complete-case results, as recommended by Manly and Wells [46] and Sterne et al. [47].

\section{Results}

\section{Descriptives and group comparisons}

Descriptive results and group differences from the complete-case group and missing-values group are presented in Table 1. Compared to the complete-case group, the missing-values group had $1.5 \%$ higher mean BMI $(p=.047)$, performed $5.9 \%$ worse on the handgrip test $(p<.001), 2.3 \%$ worse on the standing broad jump test $(p=.005)$ and had $2.9 \%$ higher CRF $(p<.001)$. The missing-values group scored $15.5 \%$ higher for TDS $(p<.001)$.

Table 1

Participant mean characteristics from the complete-case group and the missing-values group. Presented as means with standard deviations (SD).

\begin{tabular}{|c|c|c|c|c|c|c|}
\hline & $\begin{array}{l}\text { Total } \\
\text { difficulties } \\
\text { score }(0-40)\end{array}$ & $\begin{array}{l}\text { Body } \\
\text { mass } \\
\text { index }\end{array}$ & $\begin{array}{l}\text { Handgrip } \\
\text { strength } \\
(\mathrm{kg})\end{array}$ & $\begin{array}{l}\text { Standing } \\
\text { broad jump } \\
\text { (cm) }\end{array}$ & $\begin{array}{l}\text { Sit-ups } \\
\text { (n/30 } \\
\text { seconds) }\end{array}$ & $\begin{array}{l}\text { Cardio- } \\
\text { respiratory } \\
\text { fitness (meters) }\end{array}$ \\
\hline \multicolumn{7}{|l|}{$\begin{array}{l}\text { All } \\
\text { values } \\
\text { present }\end{array}$} \\
\hline $\begin{array}{l}\text { Yes }(n= \\
1486)\end{array}$ & $10.3(5.1)$ & $\begin{array}{l}19.8 \\
(3.1)\end{array}$ & $30.5(7.0)$ & $172.2(25.9)$ & $19(4)$ & $906(98)$ \\
\hline $\begin{array}{l}\text { No }(n= \\
242- \\
559)\end{array}$ & $11.9(5.7)^{\star}$ & $\begin{array}{l}20.2 \\
(3.5)\end{array}$ & $28.7(7.4)^{\star}$ & $168.2(27.8) \star$ & $19(4)$ & $932(115)^{\star}$ \\
\hline
\end{tabular}




\section{Linear mixed effects models}

Results from the linear mixed effects models are summarized in Table 3. Model 1 indicated no association between BMI and TDS. Model 2 indicated a negative association between muscular strength and TDS $(b=-.458 ; 95 \% \mathrm{Cl}:-.834$ to $-.081 ; p=.017)$. Model 3 indicated a negative association between CRF and TDS ( $b=-.006 ; 95 \% \mathrm{Cl}:-.009$ to $-.003 ; p<.001)$. The fully adjusted model with all independent variables and covariates entered simultaneously, revealed no association between muscular strength and TDS, while the association between CRF and TDS remained identical as in Model $3(b=-.006 ; 95 \% \mathrm{Cl}$ :

-.009 to $-.002 ; \mathrm{p}=.001)$. The estimates produced by the fully adjusted model suggest that every $100 \mathrm{~m}$ distance increase in the CRF test predict 0.6 points $(1.5 \%)$ lower TDS.

Table 2

Linear mixed effect models with Total difficulties score as the dependent variable.

$\begin{array}{lll}\text { Independent variable } \quad \mathrm{B}(95 \% \mathrm{Cl}) & \text { p }\end{array}$

Model 1

Body mass index

$.058(-.027$ to .142$)$

.184

Model 2

Muscular strength z score

$-.458(-.834$ to -.081$)$

Model 3

Cardiorespiratory fitness

$-.006(-.009$ to -.003$)$

$<.001$

Fully adjusted model

Intercept

17.786 (13.5 to 22.0 )

$<.001$

Body mass index

.004 (-.086 to .094$)$

.933

Muscular strength z score

- .047 (-.495 to .400)

.834

Cardiorespiratory fitness

$-.006(-.009$ to -.002$)$

.001

Note. 29 school clusters were included as random effects in all models; all models controlled for sex, socioeconomic status, and birthplace. $\mathrm{B}=$ Regression coefficient; $\mathrm{Cl}=$ Confidence interval; $\mathrm{p}=$ Significance level.

\section{Results from missing value analyses}

Among the 559 excluded participants, $12.2 \%(n=68)$ had completed the SDQ and performed the CRF test. Correlation analysis indicated a non-significant, inverse correlation between CRF and TDS $(r=-.13$; $p$ $=.139$ ), a similar relationship as in the complete-case group. Other correlations were also similar (data not shown), indicating a small likelihood of systematic differences between the complete-case group and missing-values group. 
There was a difference in missingness between test centers. One test center represented $10.7 \%$ of the participants in the complete-case group and $30.4 \%$ in the missing-values group, which means that more than half of all participants from this region were excluded due to missing values. This was caused by low completion of the SDQ, with only $13.5 \%$ of these participants completing the SDQ in the missingvalues group. The corresponding completion rates from other test centers were $51.2 \%-67.6 \%$.

Finally, the pooled dataset from the multiple imputation $(n=2045)$ was analyzed with a fully adjusted linear mixed effects model, in the same way as the complete-case dataset. The association between CRF and TDS was identical to the complete-case results $(b=-.006 ; 95 \% \mathrm{Cl}:-.010$ to $-.002 ; p=.006)$. Thus, all missing-value analyses indicated that the results likely would have been unchanged with all values present.

\section{Discussion}

The main findings of the present study were that CRF significantly predicted TDS in Norwegian adolescents while controlling for muscular strength, body composition, socioeconomic status, school clustering, sex and domestic/foreign birthplace. The results indicated that CRF was the only aspect of physical fitness associated with TDS as a measure of mental health, thus excluding body composition and muscular strength as predictors.

\section{Muscular strength, body mass index and metal health}

A significant association between muscular strength and TDS was initially found. However, when controlling for $\mathrm{CRF}$ there was no association between these variables. A possible explanation is that the participants with high CRF were also likely to have a relatively high muscular strength [48]. However, based on the fully adjusted model, it can be postulated that participants with high muscular strength did not necessarily have high CRF. A possible interpretation is that muscular strength in adolescents is generally a natural consequence of the individual's CRF level, which may represent the true association with mental health.

The present findings support previous studies that have suggested CRF to be the only health-related aspect of fitness associated with mental health outcomes such as quality of life [49], depression [27, 50] and well-being [51]. Many studies that have found associations between muscular strength and mental health outcomes in adolescents did not measure CRF [24, 52]. The present findings did not show an association between $\mathrm{BMI}$ and mental health, independent from controlling for $\mathrm{CRF}$ in the regression. This is congruent with the review by Luppino et al. [19], who found an association between overweight and depression in adults, but not in individuals younger than 20 years. This indicates a different relationship between age groups; however, it is important to point out that none of the reviewed studies controlled for CRF. Although it is possible that muscular strength and BMI are associated with mental health outcomes, studies that do not also measure CRF lack important information. Had we not controlled for all fitness variables in the present study, we would have erroneously concluded that muscular strength was 
associated with TDS. Opposing findings by Kettunen et al. [53] showed muscular strength to be more important than CRF to reduce stress in adults. However, this study categorized continuous variables and employed ANOVAs, which has been strongly advised against by Altman and Royston [54], and might have produced biased results. Additionally, associations between physical fitness and mental health might be different in adult and adolescent populations. For instance, many experimental studies have found effects of strength training on mental health in older adults [21]. Positive effects in older adults are not surprising, considering how strength training can reverse muscle atrophy and improve the daily functioning of older people [55]. In adolescents however, muscular strength is mainly associated with appearance-related mental health outcomes, such as self-perception, perceived physical appearance or physical self-worth [25]. Future studies of associations between health-related physical fitness and mental health should include different mental health outcomes, to gain a better understanding of whether specific aspects of fitness are associated with specific outcomes of mental health.

\section{Cardiorespiratory fitness and mental health}

The present findings showed that higher CRF predicted improved mental health. Although a causal direction between CRF and mental health cannot be established from cross-sectional findings, recent evidence has indicated a one-directional causal relationship for physical activity as a protective factor against depression among adults [56]. High-intensity exercise is an important factor for high CRF [16], hence results from the present study support a hypothesis suggesting that high-intensity exercise might be more favorable for mental health than low-intensity exercise. This is in accordance with the study by Parfitt, Pavey and Rowlands [57], who found high-intensity exercise to be more favorable for mental health than light-intensity exercise, in a population of children. Furthermore, the meta-analysis by Ahn and Fedewa [58] found high-intensity exercise RCT interventions to have the most effect on children's mental health. On the other hand, Helgadóttir et al. [59] concluded that low-intensity exercise was more effective on depression treatment than high-intensity exercise in an adult population. The low-intensity group exercised with yoga and this type of exercise may have a distinct relationship with mental health. However, the results should be treated with caution, because the intervention had low adherence and did not mention how this differed between exercise groups. Additionally, 12 months after the intervention, there were no significant differences between the low- and vigorous-exercise groups. The study by Helgadóttir et al. [59] is incongruent with the previously mentioned studies, as well as what Bailey et al. [60] suggested to treat depression in adolescents: "...aerobic-based activity of moderate-to-vigorous intensity." It is also possible that intensity might not even be especially crucial, as long as CRF is improved. Shepherd et al. [61] prescribed high-intensity interval training and moderate-intensity continuous training in two groups of inactive adults and both groups experienced increased CRF and improved mental health. Few studies have examined the causal relationship between increased CRF and improved mental health outcomes, but a recent longitudinal study by Rahman et al. [62] showed that improved CRF predicted at least a 50\% reduction in depression scores for adults. Ruggero et al. [22] found that high CRF at baseline was associated with lower levels of depression a year later in adolescent girls and suggested that CRF might mediate the effect physical activity has on depression. This was supported by Eddolls et al. [63] who concluded that CRF mediated the relationship between vigorous

Page 10/18 
physical activity and mental health in adolescents, thus suggesting that physical activity interventions to treat depression may only be effective if they improve CRF.

There may be several potential mechanisms underlying the associations between CRF and mental health. The endocannabinoid system, which mediates high-intensity exercise effect on depression [64], is a possible neurobiological explanation. Another potential explanatory mechanism has to do with brain function, as discussed in a recent review [65]: Depression is associated with reduced brain connectivity [66]; therefore, CRF's protective role against depression might be due to the relationship between CRF and the improved functional connectivity between regions of the brain known as the default mode network $[15,67]$. CRF in adolescents is associated with self-esteem and body satisfaction [23], and with participation in common team sports like football, handball and basketball [68], which are important arenas for social relationships. It is therefore not unlikely that the psychosocial mechanism [10] also had a mediating role in the present results. The topic of explanatory mechanisms between physical fitness and mental health requires more research, especially on adolescent populations, in order to fully understand the relationship between the relevant variables. Additionally, future studies need to examine how exercise at different intensities affects different mental health outcomes, and whether the results are influenced by increases in CRF. Such knowledge can be useful in efforts to prevent or treat mental disorders.

\subsection{Strengths and limitations}

Strengths of the present study include the large sample size from separate geographical regions, the use of three objectively measured health-related aspects of physical fitness, and the control of relevant covariates.

The main limitation of the present study was a large number of missing values; however, the extensive missing value analyses indicated that the main results most likely were unaffected by the dropouts.

The present internal consistency results pertaining to TDS were quite low and are similar to Italian [69], Finnish [70] and Dutch [36] results. Internal consistency results from English speaking populations [71,

72] are usually higher, which suggests that statements are better understood by native English speakers, while non-native English speakers may misinterpret the statements somewhat. Age is also a factor, as the internal consistency is lower for younger adolescents, such as the present population, compared to older adolescents as examined in studies by Bøe et al. [73] and Sagatun et al. [74]. Finally, the cross-sectional nature of the study limits the ability to make any causal inference.

\section{Conclusion}

The main finding from the present study was that increased cardiorespiratory fitness significantly predicted improved mental health in adolescents. Body composition was not associated with mental health. Muscular strength was initially associated with mental health but not when controlling for cardiorespiratory fitness. This indicates that strength training or focus on weight reduction may be 
ineffective in efforts to prevent or treat mental problems in adolescents. Future research in this area should examine whether changes in cardiorespiratory fitness affect mental health in adolescents, and whether different exercise intensities affect adolescents' mental health differently.

\section{Declarations}

- Ethics approval and consent to participate: The project was reviewed by the Regional Committee for Medical and Health Research Ethics (REK) in Norway, who according to the Act on medical and health research (the Health Research Act 2008) concluded that the study did not require full review by REK. The study was approved by the Norwegian Centre for Research Data. Written informed consent from the participants and their parents or caretakers was obtained prior to the data collection

- Consent for publication: Not applicable

- Availability of data and material: The datasets generated and/or analyzed during the current study are not publicly available as publications are planned but are available from the corresponding author on reasonable request.

- Competing interests: The authors declare that they have no competing interests.

- Funding: The study was funded by grants from the Norwegian Directorate for Education and Training.

- Authors' contributions: Each author has contributed to the conception and design of the work. All authors participated in writing of the paper and approved the final version.

\section{References}

1. WHO. Mental health: a state of well-being: World Health Organization; 2014 [updated 2014-08-15 15:25:38. Available from: http://www.who.int/features/factfiles/mental_health/en/.

2. Kieling C, Baker-Henningham H, Belfer M, Conti G, Ertem I, Omigdobun O, et al. Child and adolescent mental health worldwide: evidence for action. Lancet. 2011;378:1515-25.

3. Steel Z, Marnane C, Iranpour C, Chey T, Jackson J, Patel V, et al. The global prevalence of common mental disorders: a systematic review and meta-analysis 1980-2013. Int J Epidemiol. 2014;43(2):476-93.

4. Whiteford HA, Degenhardt L, Rehm J, Baxter AJ, Ferrari AJ, Erskine HE, et al. Global burden of disease attributable to mental and substance use disorders: findings from the Global Burden of Disease Study 2010. The Lancet. 2013;382(9904):1575-86.

5. Collishaw S. Annual Research Review: Secular trends in child and adolescent mental health. Journal of Child Psychology and Psychiatry. 2015;56(3):370-93. 
6. Bakken A. Ungdata. Nasjonale resultater 2017. Oslo: NOVA; 2017.

7. Mammen G, Faulkner G. Physical Activity and the Prevention of Depression: A Systematic Review of Prospective studies. American Journal of Preventive Medicine. 2013;45(5):649-57.

8. Basso JC, Suzuki WA. The Effects of Acute Exercise on Mood, Cognition, Neurophysiology, and Neurochemical Pathways: A Review. Brain Plasticity. 2017;2(2):127-52.

9. Mingli L, Lang W, Qingsen M. How Does Physical Activity Intervention Improve Self- Esteem and SelfConcept in Children and Adolescents? Evidence from a Meta-Analysis. PLoS ONE. 2015;10(8):e0134804.

10. Lubans DR, Richards J, Hillman C, Faulkner G, Beauchamp M, Nilsson M, et al. Physical Activity for Cognitive and Mental Health in Youth: A Systematic Review of Mechanisms. Pediatrics. 2016;138(3):e20161642.

11. Fisher A, Smith L, van Jaarsveld CHM, Sawyer A, Wardle J. Are children's activity levels determined by their genes or environment? A systematic review of twin studies. Preventive medicine reports. 2015;2:548-53.

12. Blair SN, Cheng Y, Holder JS. Is physical activity or physical fitness more important in defining health benefits? Med Sci Sports Exerc. 2001;33(6, Suppl.):379-99.

13. Caspersen CJ, Powell KE, Christenson GM. Physical activity, exercise and physical fitness: Definitions and distinctions for health-related research. Public Health Reports. 1985;100(2):126-30.

14. Silverman MN, Deuster PA. Biological mechanisms underlying the role of physical fitness in health and resilience. Interface Focus. 2014;4(5).

15. Voss MW, Weng TB, Burzynska AZ, Wong CN, Cooke GE, Clark R, et al. Fitness, but not physical activity, is related to functional integrity of brain networks associated with aging. Neurolmage. 2016;131:113-25.

16. Silva G, Andersen LB, Aires L, Mota J, Oliveira J, Ribeiro JC. Associations between sports participation, levels of moderate to vigorous physical activity and cardiorespiratory fitness in children and adolescents. Journal of Sports Sciences. 2013;31(12):1359-67.

17. Streeter VM, Milhausen RR, Buchholz AC. Body Image, Body Mass Index, and Body Composition: In Young Adults. Canadian Journal of Dietetic Practice and Research. 2012;73(2):78-83.

18. Grabe S, Ward LM, Hyde JS. The role of the media in body image concerns among women: A metaanalysis of experimental and correlational studies. Psychological Bulletin. 2008;134(3):460-76.

19. Luppino FS, de Wit LM, Bouvy PF, Stijnen T, Cuijpers P, Phennix BWJH, et al. Overweight, obesity, and depression: A systematic review and meta-analysis of longitudinal studies. Archives of General Psychiatry. 2010;67(3):220-9.

20. Rodgers RF, Ganchou C, Franko DL, Chabrol H. Drive for muscularity and disordered eating among French adolescent boys: A sociocultural model. Body Image. 2012;9(3):318-23.

21. O'Connor PJ, Herring MP, Caravalho A. Mental Health Benefits of Strength Training in Adults. American Journal of Lifestyle Medicine. 2010;4(5):377-96. 
22. Ruggero CJ, Petrie T, Sheinbein S, Greenleaf C, Martin S. Cardiorespiratory Fitness May Help in Protecting Against Depression Among Middle School Adolescents. Journal of Adolescent Health. 2015;57(1):60-5.

23. Greenleaf C, Petrie T, Martin SB. Psychosocial Variables Associated With Body Composition and Cardiorespiratory Fitness in Middle School Students. Research Quarterly for Exercise and Sport. 2010;81:65-74.

24. Lubans DR, Cliff DP. Muscular fitness, body composition and physical self-perception in adolescents. Journal of Science and Medicine in Sport. 2011;14(3):216-21.

25. Smith JJ, Eather N, Morgan PJ, Plotnikoff RC, Faigenbaum AD, Lubans DR. The Health Benefits of Muscular Fitness for Children and Adolescents: A Systematic Review and Meta-Analysis. J Sports Medicine. 2014;44(9):1209-23.

26. Patel V, Flisher AJ, Hetrick S, McGorry P. Mental health of young people: a global public- health challenge. Lancet. 2007;369(9569):1302.

27. Yeatts PE, Martin SB, Petrie TA. Physical fitness as a moderator of neuroticism and depression in adolescent boys and girls. Personality and Individual Differences. 2017;114:30-5.

28. Haugen $T$, Ommundsen $Y$, Seiler $S$. The relationship between physical activity and physical selfesteem in adolescents: the role of physical fitness indices. Pediatric exercise science. 2013;25(1):138-53.

29. Kolle, E., Solberg, R. B., Grydeland, M., Säfvenbom, R., Anderssen, S. A., Ekelund, U., Berntsen, S., Resaland, G. K., Dyrstad, S. M. \& Steene-Johannessen, J. Evaluating the effect of increased physical activity in lower secondary school adolescents: The study protocol for the School in Motion (ScIM) study - a cluster-randomized controlled trial. Mansucript submitted for publication. 2020.

30. Council of Europe. Handbook of the Eurofit tests of Physical Fitness. Roma Italian National. 1988.

31. Andersen L, Andersen TE, Andersen E, Anderssen S. An intermittent running test to estimate maximal oxygen uptake: the Andersen test. Journal of Sports Medicine and Physical Fitness. 2008;48(4):4347.

32. Goodman R. The Strengths and Difficulties Questionnaire: A Research Note. Journal of Child Psychology and Psychiatry. 1997;38(5):581-6.

33. Goodman A, Goodman R. Strengths and Difficulties Questionnaire as a Dimensional Measure of Child Mental Health. Journal of the American Academy of Child \& Adolescent Psychiatry. 2009;48(4):400-3.

34. Rothenberger A, Becker A, Erhart M, Wille N, Ravens-Sieberer U. Psychometric properties of the parent strengths and difficulties questionnaire in the general population of German children and adolescents: results of the BELLA study. European Child \& Adolescent Psychiatry. 2008;17(1):99.

35. Goodman R. Psychometric Properties of the Strengths and Difficulties Questionnaire. Journal of the American Academy of Child \& Adolescent Psychiatry. 2001;40(11):1337-45.

36. Muris P, Meesters C, Eijkelenboom A, Vincken M. The self-report version of the Strengths and Difficulties Questionnaire: Its psychometric properties in 8- to 13-year-old non-clinical children. $\mathrm{Br} \mathrm{J}$ 
Clin Psychol. 2004;43:437-48.

37. Van Roy B, Veenstra M, Clench-Aas J. Construct validity of the five-factor Strengths and Difficulties Questionnaire (SDQ) in pre-, early, and late adolescence. Journal of child psychology and psychiatry, and allied disciplines. 2008;49(12):1304-12.

38. Bakken A. Ungdata. Nasjonale resultater 2018. Oslo: NOVA; 2018.

39. Abebe DS, Lien L, Hjelde KH. What We Know and Don't Know About Mental Health Problems Among Immigrants in Norway. Journal of Immigrant Minority Health. 2014;16(1):60-7.

40. Bøe T, Øverland S, Lundervold AJ, Hysing M. Socioeconomic status and children's mental health: results from the Bergen Child Study. Soc Psychiatry Psychiatr Epidemiol. 2012;47(10):1557-66.

41. Erola J, Jalonen S, Lehti H. Parental education, class and income over early life course and children's achievement. Research in Social Stratification and Mobility. 2016;44:33-43.

42. Youthinmind. Information for researchers and professionals about the Strengths \& Difficulties Questionnaires 2018. Available from: http://www.sdqinfo.com/.

43. Altman DG, Bland JM. Missing data. BMJ (Clinical research ed). 2007;334(7590):424-.

44. Rubin DB. Multiple Imputation After 18+ Years. Journal of the American Statistical Association. 1996;91(434):473-89.

45. Pedersen AB, Mikkelsen EM, Cronin-Fenton D, Kristensen NR, Pham TM, Pedersen L, et al. Missing data and multiple imputation in clinical epidemiological research. Clinical Epidemiology. 2017;9:15766.

46. Manly CA, Wells RS. Reporting the Use of Multiple Imputation for Missing Data in Higher Education Research. Research in Higher Education. 2015;56(4):397-409.

47. Sterne JAC, White IR, Carlin JB, Spratt M, Royston P, Kenward MG, et al. Multiple imputation for missing data in epidemiological and clinical research: potential and pitfalls. The BMJ. 2009;338:b2393.

48. Moliner-Urdiales D, Ruiz JR, Vicente-Rodriguez G, Ortega FB, Rey-Lopez JP, España-Romero V, et al. Associations of muscular and cardiorespiratory fitness with total and central body fat in adolescents: The HELENA Study. 2011;45(2):101-8.

49. Andersen JR, Natvig GK, Aadland E, Moe VF, Kolotkin RL, Anderssen SA, et al. Associations between health-related quality of life, cardiorespiratory fitness, muscle strength, physical activity and waist circumference in 10-year-old children: the ASK study. Quality of Life Research. 2017;26(12):3421-8.

50. Rieck T, Jackson A, Martin SB, Petrie T, Greenleaf C. Health-related Fitness, Body Mass Index, and Risk of Depression among Adolescents. Medicine \& Science in Sports \& Exercise. 2013;45(6):1083-8.

51. Kelly NR, Mazzeo SE, Evans RK, Stern M, Thacker LF, Thornton LM, et al. Physical activity, fitness and psychosocial functioning of obese adolescents. Mental Health and Physical Activity. 2010;4(1):31-7.

52. Padilla-Moledo C, Ruiz JR, Ortega FB, Mora J, Castro-Pinero J. Associations of muscular fitness with psychological positive health, health complaints, and health risk behaviors in Spanish children and adolescents. Journal of strength and conditioning research. 2012;26(1):167-73. 
53. Kettunen O, Kyröläinen H, Santtila M, Vuorimaa T, Vasankari TJ. Greater levels of cardiorespiratory and muscular fitness are associated with low stress and high mental resources in normal but not overweight men. BMC Public Health. 2016;16:788.

54. Altman DG, Royston P. The cost of dichotomising continuous variables. BMJ (Clinical research ed). 2006;332(7549):1080.

55. Fiatarone MA, Marks EC, Ryan ND, Meredith CN, Lipsitz LA, Evans WJ. High-intensity strength training in nonagenarians: Effects on skeletal muscle. JAMA. 1990;263(22):3029-34.

56. Choi KW, Chen C-Y, Stein MB, Klimentidis YC, Wang M-J, Koenen KC, et al. Assessment of bidirectional relationships between physical activity and depression among adults: A 2-sample mendelian randomization study. JAMA Psychiatry. 2019;76(4):399-408.

57. Parfitt G, Pavey T, Rowlands AV. Children's physical activity and psychological health: the relevance of intensity. Acta Pædiatrica. 2009;98(6):1037-43.

58. Ahn S, Fedewa AL. A Meta-analysis of the Relationship Between Children's Physical Activity and Mental Health. J Pediatr Psychol. 2011;36:385-97.

59. Helgadóttir B, Forsell Y, Hallgren M, Möller J, Ekblom Ö. Long-term effects of exercise at different intensity levels on depression: A randomized controlled trial. Preventive Medicine. 2017;105:37-46.

60. Bailey AP, Hetrick SE, Rosenbaum S, Purcell R, Parker AG. Treating depression with physical activity in adolescents and young adults: a systematic review and meta-analysis of randomised controlled trials. Psychological medicine. 2017;48(7):1-20.

61. Shepherd SO, Wilson OJ, Taylor AS, Thøgersen-Ntoumani C, Adlan AM, Wagenmakers AJM, et al. Low-Volume High-Intensity Interval Training in a Gym Setting Improves Cardio-Metabolic and Psychological Health. PLOS ONE. 2015;10(9):e0139056.

62. Rahman MS, Helgadóttir B, Hallgren M, Forsell Y, Stubbs B, Vancampfort D, et al. Cardiorespiratory fitness and response to exercise treatment in depression. BJPsych Open. 2018;4(5):346-51.

63. Eddolls WTB, McNarry MA, Lester L, Winn CON, Stratton G, Mackintosh KA. The association between physical activity, fitness and body mass index on mental well-being and quality of life in adolescents. Quality of Life Research. 2018;27(9):2313-20.

64. Heyman E, Gamelin FX, Goekint M, Piscitelli F, Roelands B, Leclair E, et al. Intense exercise increases circulating endocannabinoid and BDNF levels in humans-Possible implications for reward and depression. Psychoneuroendocrinology. 2012;37(6):844-51.

65. Schuch FB, Vancampfort D, Sui X, Rosenbaum S, Firth J, Richards J, et al. Are lower levels of cardiorespiratory fitness associated with incident depression? A systematic review of prospective cohort studies. Preventive Medicine. 2016;93:159-65.

66. Zhang H, Li L, Wu M, Chen Z, Hu X, Chen Y, et al. Brain gray matter alterations in first episodes of depression: A meta-analysis of whole-brain studies. Neuroscience \& Biobehavioral Reviews. 2016;60:43-50.

67. Raichle ME, MacLeod AM, Snyder AZ, Powers WJ, Gusnard DA, Shulman GL. A default mode of brain function. Proceedings of the National Academy of Sciences. 2001;98(2):676-82. 
68. Tammelin T, Näyhä S, Hills AP, Järvelin M-R. Adolescent participation in sports and adult physical activity. American Journal of Preventive Medicine. 2003;24(1):22-8.

69. Riso DD, Salcuni S, Chessa D, Raudino A, Lis A, Altoè G. The Strengths and Difficulties Questionnaire (SDQ). Early evidence of its reliability and validity in a community sample of Italian children. Personality and Individual Differences. 2010;49(6):570-5.

70. Koskelainen M, Sourander A, Vauras M. Self-reported strengths and difficulties in a community sample of Finnish adolescents. J European Child \& Adolescent Psychiatry. 2001;10(3):180-5.

71. Goodman R, Meltzer H, Bailey V. The Strengths and Difficulties Questionnaire: a pilot study on the validity of the self-report version. 2003;15(1-2):173-7.

72. Ruchkin V, Jones S, Vermeiren R, Schwab-Stone M. The strengths and difficulties questionnaire: The self-report version in American urban and suburban youth. Psychological Assessment. 2008;20(2):175-82.

73. Bøe T, Hysing M, Skogen J, Breivik K. The Strengths and Difficulties Questionnaire (SDQ): Factor Structure and Gender Equivalence in Norwegian Adolescents. PLoS One. 2016;11(5):e0152202.

74. Sagatun A, Søgaard AJ, Bjertness E, Selmer R, Heyerdahl S. The association between weekly hours of physical activity and mental health: A three-year follow-up study of 15-16-year-old students in the city of Oslo, Norway. BMC Public Health. 2007;7(1).

\section{Figures}




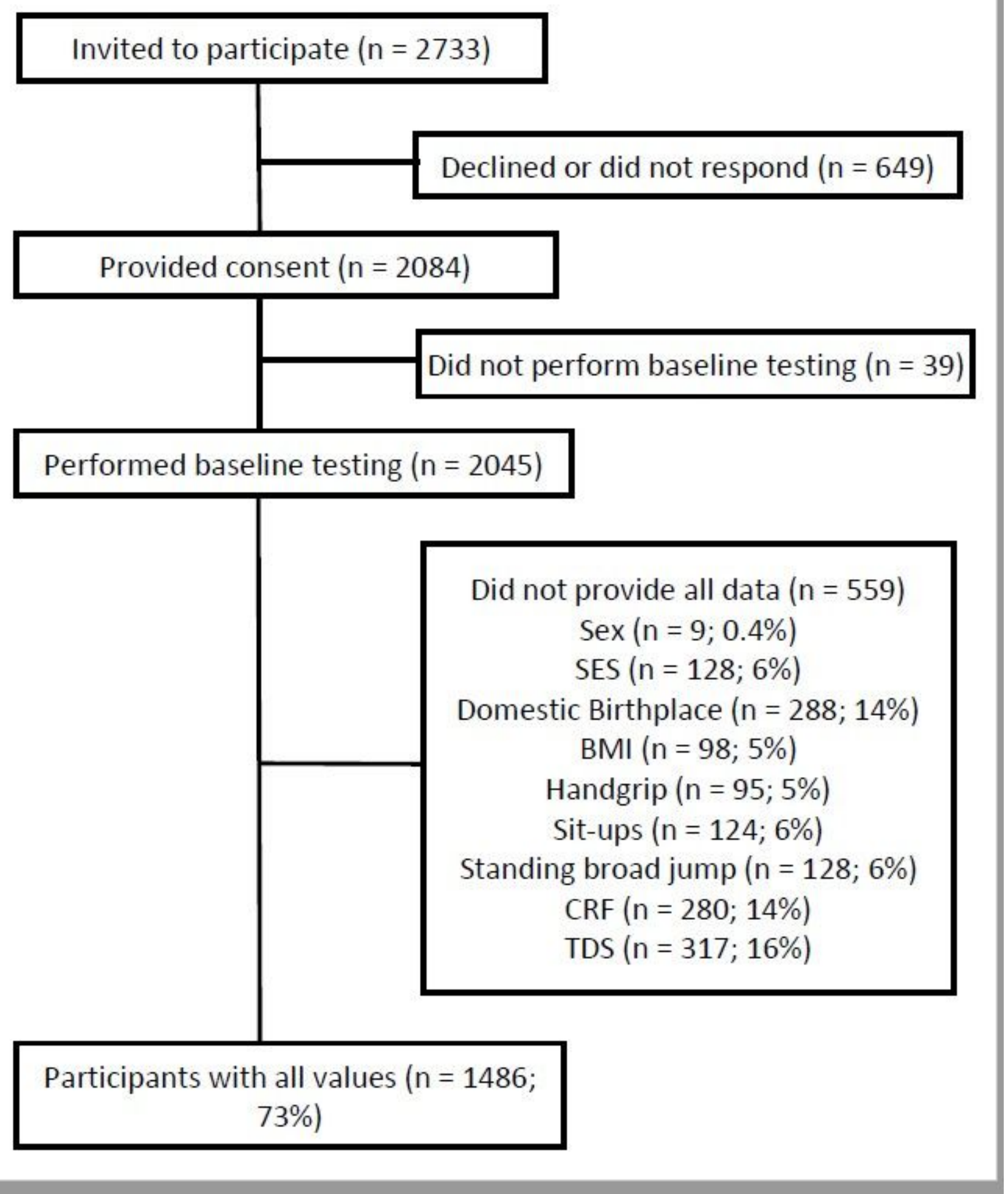

Figure 1

physical fitness, mental health, strengths and difficulties, Norway, adolescence, cross-sectional 